\title{
The future of legal pot
}

Cite as: CMAJ 2017 June 5;189:E788-9. doi: 10.1503/cmaj.1095424

\section{Part I: The public health perspective}

t remains uncertain exactly how the recreational marijuana market will operate in Canada, though the federal government provided a glimpse in its proposed bill to legalize cannabis.

Physicians and medical researchers wonder how legalization, slated to become law in July 2018, will affect public health. Marijuana producers want to know, among other things, how advertising and branding will be regulated. Marijuana activists, who have long advocated for legalization, are concerned about restrictions in the proposed legislation.

CMAJ asked various stakeholders about their concerns over the proposed federal legislation. The first part of this two-part article explores the medical community's perspective. Part two will examine the concerns of marijuana producers and advocates.

\section{A public-health focus}

Physicians and researchers are advocating for a recreational market that operates through a public-health lens. Some are concerned that the proposed legislation may be more focused on building a lucrative commercial sector than protecting the health of Canadians, young people in particular.

"We are troubled by several aspects of the new legislation," Michael Devillaer and James Mackillop of the Peter Boris Centre for Addictions Research said to CMAJ in a joint statement. The centre recently published the report Cannabis Law Reform in Canada: Pretense \& Perils.

By setting the minimum age to purchase marijuana legally at 18 instead of higher, the government appears to be overlooking credible evidence that cannabis use can have negative effects on young people's neurocognitive development, said the researchers.
Also, the government did not ban advertising, as recommended by many public health organizations. This will allow cannabis producers to target specific market segments, such as women, former users and curiosity-seekers. The researchers are also concerned about how legalization will affect the medical cannabis sector, which they say should operate within the health care system.

"In setting the legal age of access at 18 and not banning advertising, the Cannabis Act appears too industry-friendly, at the potential expense of public health," according to Devillaer and Mackillop. "In sum, the legalization of cannabis presents a many-headed hydra from a public health and legal perspective.
Although the Task Force [on Cannabis Legalization and Regulation] and Cannabis Act address many aspects, major gaps remain present."

The Canadian Medical Association (CMA) also adopted a public health stance, on the marijuana bill, stating in a media release that the government "must focus first and foremost on protecting Canadians and reducing any potential harms to health." The CMA highlighted the particular risk of cannabis use on the brain development of youth, and recommended a broad public-health-policy approach that would include efforts to prevent abuse and dependence, enhance research and monitoring, and provide treatment and harm-reduction services.

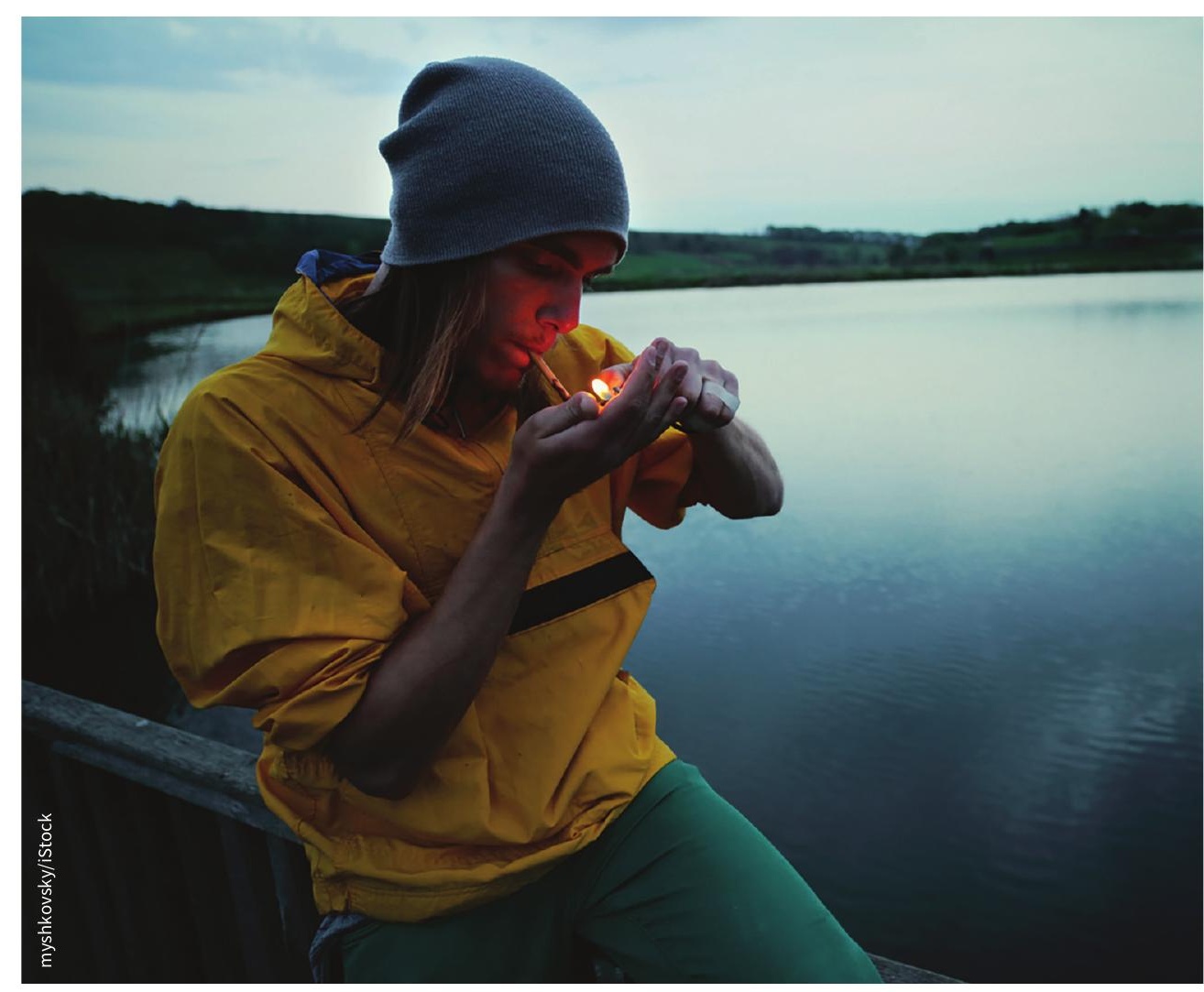

Some physicians and health researchers think the minimum age to purchase marijuana should be higher than 18 years old. 
Though the proposed bill is federal, it will be left to the provinces to design their distribution systems for retail marijuana, and that is no trivial task, according to Dr. Benedikt Fischer, a senior scientist with the Centre for Addiction and Mental Health. In an opinion piece in The Globe and Mail, he wrote that "getting the design of retail models right will be crucial for whether legalization will work for or against the paramount goal of furthering public health." A public-healthfocused distribution system would be free of advertising, promote low-risk use and have pricing that brings users to the legal market but keeps demand low, according to Fischer.

In Ontario, the provincially run Liquor Control Board of Ontario (LCBO) should be at the core of marijuana distribution, recommended Fischer. It has the infrastructure, experience handling a psychoactive substance and the backing of Ontario Premier Kathleen Wynne. "Hence, it is a readyto-go system well designed for the safe and sensible distribution of cannabis products," he wrote.

Private dispensaries and corner stores are also distribution options, though they would have to be held to certain stan- dards, such as allowing purchase only within a limited number of hours a day. In addition, the marijuana products should be stored behind the counter and handled only by trained staff. The Retail Council of Canada is consulting with retailors and governments on this issue.

The storefront option, however, is not a popular one with some health advocates. The ease of availability could encourage overuse of marijuana. Also, it would be harder for regulators to ensure that hundreds of small businesses and private dispensaries, as compared to a single government-run entity like the $\mathrm{LCBO}$, are adhering to rules governing advertising, marketing, branding, serving sizes, potency and packaging.

There have also been concerns raised about the safety and sources of marijuana sold in storefront dispensaries, which are and will remain illegal until the proposed legislation passes. When asked about this form of distribution last year, Michel Picard, a Member of Parliament and member of the Standing Committee on Public Safety and National Security, said, "These storefronts sell untested products that may be unsafe and of particular risk to kids and they are supplied by illegal growers."
Another option for recreational distribution is via online orders. Or the recreational market could follow the lead of the medical stream and provide access by mail order. These channels would need to be safe and secure, however, and would have to be implemented to ensure youth can't gain access.

The federal government has already stated, in fact, that online sales will be restricted. You will need more than a few cannabis plants and an Internet connection to enter this part of the commercial market. The proposed legislation states that only "federally licensed producers" will be permitted to sell online, and those producers must be able to provide "secure home delivery through the mail or by courier."

The Canadian Association for Pharmacy Distribution Management, which supplies medicines for drugstores and hospitals, has suggested that its existing distribution system would be superior to mail order for moving cannabis. The association's CEO, David Johnston, has stated that it already has the infrastructure to handle recalls in any part of the country, even rural areas.

Roger Collier, CMAJ 